\title{
(2) OPEN ACCESS \\ Carbon footprint impact of the choice of inhalers for asthma and COPD
}

\author{
Christer Janson (1) , ${ }^{1}$ Richard Henderson, ${ }^{2}$ Magnus Löfdahl, ${ }^{3}$ Martin Hedberg, ${ }^{4}$ \\ Raj Sharma, ${ }^{5}$ Alexander J K Wilkinson (i) ${ }^{6}$
}

'Department of Medical

Sciences: Respiratory, Allergy and Sleep Research, Uppsala

University, Uppsala, Sweden

${ }^{2}$ Environment, Health,

Safety and Sustainability,

GlaxoSmithKline, Brentfor,

London, UK

${ }^{3}$ Worldwide Medical Affairs Europe Mid Size \& Cluster

$R \& D$, GlaxoSmithKline, Solna, Stockholm, Sweden

${ }^{4}$ Meteorologist, The Polyfuture Institute SWC AB, Nacka,

Sweden

${ }^{5}$ Respiratory Medical Franchise, GlaxoSmithKline, Brentford, London, UK

${ }^{6}$ Respiratory Department, East and North Hertfordshire NHS

Trust, Stevenage, UK

\section{Correspondence to}

Dr Christer Janson, Dep om Medical Sciences: Respiratory Medicine, Uppsala University, Uppsala 752 36, Sweden; christer.janson@medsci.uu.se

Received 24 June 2019 Revised 25 August 2019 Accepted 16 October 2019 Published Online First

7 November 2019

\section{Check for updates}

(C) Author(s) (or their employer(s)) 2020. Re-use permitted under CC BY-NC. No commercial re-use. See rights and permissions. Published by BMJ.

\section{To cite: Janson $C$,}

Henderson R, Löfdahl M

et al. Thorax 2020;75:82-84.

\section{ABSTRACT}

In the 1990s, metered dose inhalers (MDIs) containing chlorofluorocarbons were replaced with dry-powder inhalers (DPIs) and MDIs containing hydrofluorocarbons (HFCs). While HFCs are not ozone depleting, they are potent greenhouse gases. Annual carbon footprint $\left(\mathrm{CO}_{2} \mathrm{e}\right)$, per patient were $17 \mathrm{~kg}$ for Relvar-Ellipta/VentolinAccuhaler; and $439 \mathrm{~kg}$ for Seretide-Evohaler/VentolinEvohaler. In 2017, 70\% of all inhalers sold in England were MDI, versus 13\% in Sweden. Applying the Swedish $\mathrm{DPI}$ and MDI distribution to England would result in an annual reduction of $550 \mathrm{kt} \mathrm{CO}_{2}$ e. The lower carbon footprint of DPIs should be considered alongside other factors when choosing inhalation devices.

\section{INTRODUCTION}

Until the early 1990s, metered dose inhalers (MDIs) that contained chlorofluorocarbons (CFCs) as propellant were the most common way to administer inhaled therapy for asthma and chronic obstructive pulmonary disease (COPD). In 1987, the Montreal Protocol on Substances that Deplete the Ozone Layer included the phasing out of CFCs, ${ }^{1}$ warranting the development of new ways to deliver inhaled therapy for asthma and COPD. This included dry-powder inhalers (DPIs), CFCfree MDIs that used hydrofluorocarbons (HFCs) as a propellant and, aqueous/soft mist inhalers.

Studies of prescription patterns in Europe have found large differences among countries in choice of inhalation device. A study published in 2011 concluded that approximately $90 \%$ of inhaled corticosteroid (ICS) devices used in Sweden were DPIs, whereas in the UK, approximately $80 \%$ were MDIs. ${ }^{2}$

Unlike CFCs, HFCs are not ozone-depleting substances but they are still greenhouse gases that have a high global warming potential (GWP). In 2017, the British Thoracic Society issued a statement to encourage prescribers and patients to consider switching pressurised MDIs to non-propellant devices because of this difference in environmental impact. This statement was recently updated. ${ }^{3}$

This study aimed to compare the environmental impact of DPI and MDI combinations using calculated carbon footprint data for two DPIs, Ellipta and Accuhaler, and one MDI, Evohaler. A secondary aim was to compare the inhaler-related carbon footprint impact between England and Sweden and the potential for reduction of annual carbon footprint $\left(\mathrm{CO}_{2} \mathrm{e}\right)$ in England if the pattern of inhalation devices chosen in England were to resemble that in Sweden.

\section{METHODS}

The $\mathrm{CO}_{2} \mathrm{e}$ of average use of three ICS and longacting $\beta 2$-agonist combinations Relvar ${ }^{*}$ Ellipta (fluticasone furorate/vilanterol) (DPI), Seretide" Accuhaler (fluticasone propionate/salmeterol) (DPI), Seretide Evohaler (MDI) and two short acting 32 -agonists Ventolin "Accuhaler (salbutamol) (MDI), and Ventolin Evohaler (MDI) in asthma and COPD have been estimated based on individually produced carbon footprints by GlaxoSmithKline and certified by the Carbon Trust. This was achieved by taking into account the whole life cycle of the device: production of pharmaceutical ingredients and the final product, packaging of product, distribution and storage, use and disposal (online supplementary file).

Data on the prescriptions dispensed of inhalation devices in England and Sweden in 2017 was collected. In England, the prescription cost analysis that included prescriptions of 49994877 inhalers from the National Health Service for 2017 was used, ${ }^{4}$ and in Sweden the corresponding data including 4771689 inhalers were obtained from IQVIVA, Stockholm, Sweden. The annual $\mathrm{CO}_{2}$ e for inhalation devices in England was estimated by assuming a carbon footprint for MDIs of $20 \mathrm{~kg} \mathrm{CO} \mathrm{CO}_{2} \mathrm{e}$ and a carbon footprint for DPIs of $1 \mathrm{~kg} \mathrm{CO}_{2} \mathrm{e}$ per inhaler; these values were approximated from carbon footprint data calculated for GlaxoSmithKline devices (online supplementary file). The potential reduction in carbon footprint was estimated by recalculating what the carbon footprint of inhalers in England would be if MDIs and DPIs were prescribed in the same proportions as in Sweden.

\section{RESULTS}

The Evohaler MDIs had 20-30 times larger carbon footprints than the Accuhaler and Elipta DPIs (table 1). This difference was mainly related to the use phase (treatment) and the end of life phase (disposal) when the propellant is released.

The combination of Relvar Ellipta $\left(9.5 \mathrm{~kg} \mathrm{CO}_{2} \mathrm{e}\right)$ and Ventolin Accuhaler (7.3 $\mathrm{kg} \mathrm{CO}_{2} \mathrm{e}$ ) had an annual carbon footprint of $17 \mathrm{~kg} \mathrm{CO}_{2} \mathrm{e}$, while the corresponding value for using the combination Seretide Evohaler $\left(234 \mathrm{~kg} \mathrm{CO} \mathrm{CO}_{2} \mathrm{e}\right.$ ) and Ventolin Evohaler (205 $\mathrm{kg} \mathrm{CO}_{2} \mathrm{e}$ ) was $439 \mathrm{~kg} \mathrm{CO}_{2} \mathrm{e}$ (figure 1).

In England in 2017, 70\% of all inhalers sold were MDI, whereas the corresponding figure for Sweden was 13\%. The difference was largest for SABA: 94 versus 10\% MDIs in England and Sweden respectively, while the corresponding difference for devices that contained ICS was 62 versus 14\%. 
Table 1 Contribution of phases in the life cycle of different inhaler devices to their individual carbon footprint (net kg $\mathrm{CO}_{2} \mathrm{e} / \mathrm{per}$ pack) and annual carbon footprints of each device

\begin{tabular}{|c|c|c|c|c|c|}
\hline & $\begin{array}{l}\text { RELVAR } \\
\text { ELLIPTA } \\
92 / 22 \mu \mathrm{g}\end{array}$ & $\begin{array}{l}\text { SERETIDE } \\
\text { ACCUHALER } \\
50 / 500 \mu \mathrm{g}\end{array}$ & $\begin{array}{l}\text { VENTOLIN } \\
\text { ACCUHALER } \\
200 \mu \mathrm{g}\end{array}$ & $\begin{array}{l}\text { SERETIDE } \\
\text { EVOHALER } \\
25 / 250 \mu \mathrm{g}\end{array}$ & $\begin{array}{l}\text { VENTOLIN } \\
\text { EVOHALER } \\
100 \mu \mathrm{g}\end{array}$ \\
\hline Active pharmaceutical ingredients & 0.02 & 0.25 & 0.02 & 0.08 & 0.10 \\
\hline Manufacturing & 0.73 & 0.46 & 0.42 & 2.12 & 1.11 \\
\hline Distribution & 0.03 & 0.06 & 0.02 & 0.03 & 0.02 \\
\hline User phase & 0.00 & 0.12 & 0.12 & 10.68 & 19.39 \\
\hline End of life & 0.03 & 0.01 & 0.01 & 6.08 & 7.38 \\
\hline Net kg CO 2 e/pack & 0.80 & 0.90 & 0.60 & 19.00 & 28.00 \\
\hline Net kg CO 2 e/year & 9.5 & 11.0 & $7.3^{*}$ & 234.0 & $205.0^{*}$ \\
\hline
\end{tabular}

*If using on average two doses per day.

If England had the same rates of MDI use as Sweden, $550 \mathrm{kt}$ $\mathrm{CO}_{2}$ e would be saved annually (table 2 ).

\section{DISCUSSION}

Using Ellipta and Accuhaler DPIs instead of Evohaler MDIs resulted in an annual carbon footprint reduction equivalent to $422 \mathrm{~kg} \mathrm{CO}$ e per patient. Applying the Swedish DPI and MDI distribution to England would result in an estimated annual reduction of $550 \mathrm{kt} \mathrm{CO}_{2}$ e annually.

The impact of HFCs from inhalers on overall greenhouse gas emissions can be viewed from many perspectives. Internationally, HFC release from MDIs in 2014 was equivalent to 0.013 gt $\mathrm{CO}_{2} \mathrm{e}$, which was about $3 \%$ of global GWP-weighted $\mathrm{CO}_{2} \mathrm{e}$ emissions of HFCs. ${ }^{5}$ HFCs are also used as refrigerants in refrigeration, air-conditioning and heat pump equipment (80\%); as blowing agents for foams (11\%); as solvents and in fire extinguishers $(5 \%){ }^{6}$ From an individual patient's perspective, a comparison of Ventolin and Seretide Evohalers with Relvar
Ellipta and Ventolin Accuhaler could save $422 \mathrm{~kg} \mathrm{CO}_{2}$ e per year per patient. This is similar to the per capita carbon reductions obtained if changing from a meat-based to a plant-based diet. ${ }^{7}$ This calculation was based on a usage of two doses SABA per day. ${ }^{8}$ In patients that are very well controlled and therefore not using any SABA at all the difference was $234 \mathrm{~kg} \mathrm{CO}_{2}$ e per year.

We found a large difference between England and Sweden in the distribution of inhalation devices. This is in accordance with previous data. ${ }^{2}$ The reason for this difference is not entirely clear but could be related to marketing strategies and prescribers' and patients' biases. ${ }^{2}$ In England, the carbon footprint of the National Health Service (NHS) is $\approx 23 \mathrm{mt} \mathrm{CO}$ e. Pharmaceuticals procurement is $16 \%$ of the footprint, one quarter of which comes from MDIs. ${ }^{9}$ Other carbon footprint sources include building and energy and travel (4.6 and $2.8 \mathrm{mt} \mathrm{CO}_{2} \mathrm{e}$, respectively). The predicted reduction of $550 \mathrm{kt} \mathrm{CO}_{2} \mathrm{e}$ annually that we calculated by applying the Swedish distribution of inhalation devices to the population in England thus corresponds
$\mathrm{Kg} \mathrm{CO}_{2} \mathrm{e} /$ year

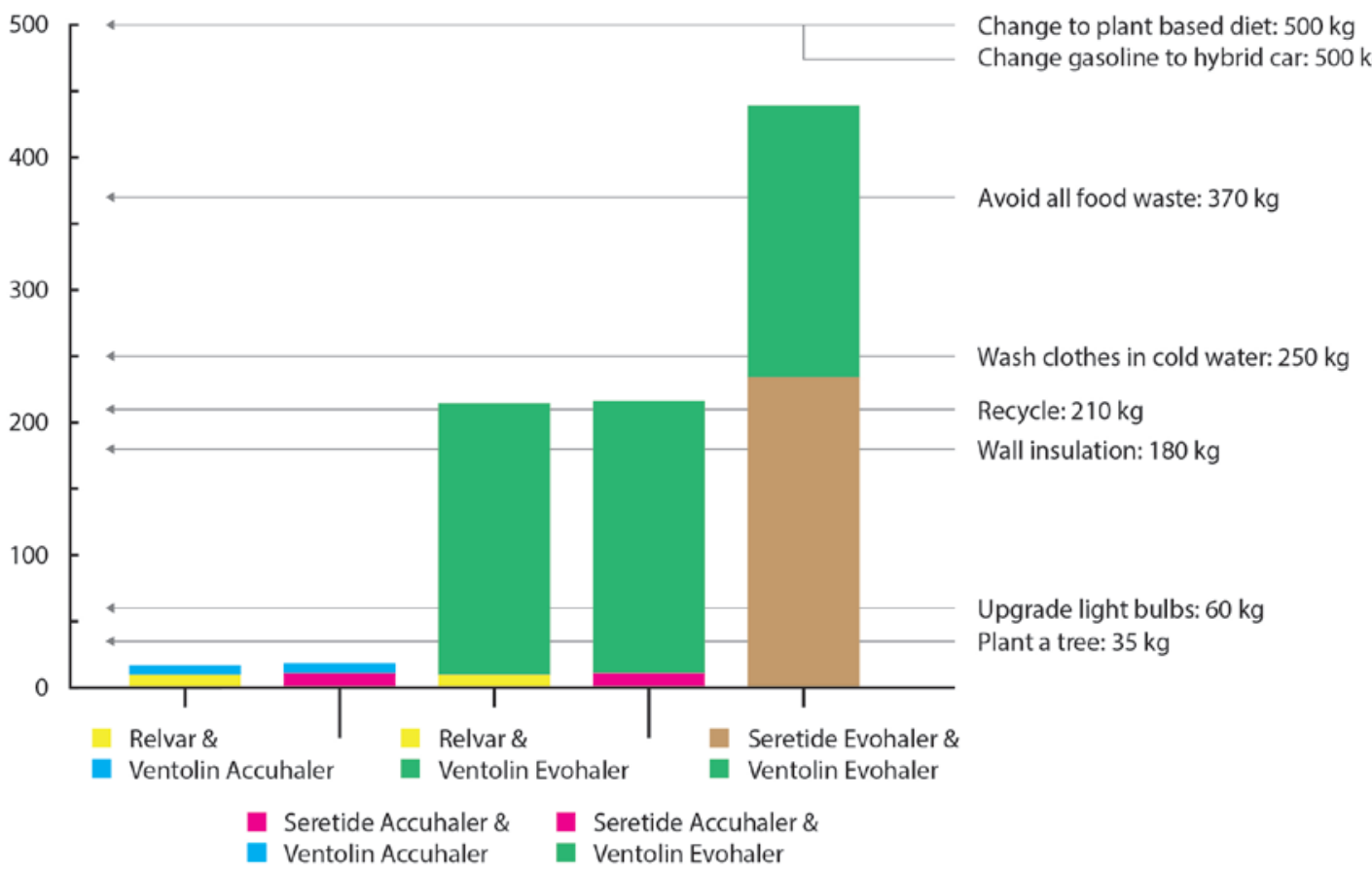

\section{$\mathrm{CO}_{2}$ e saving effect/year}

Change to plant based diet: $500 \mathrm{~kg}$

$500 \mathrm{~kg}$

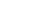


Table 2 Proportion of MDI use in different classes and potential reduction in kilo tons $(\mathrm{kt})$ of $\mathrm{CO}_{2} \mathrm{e}$ if changing the proportion of MDI use in the England to the level of Sweden

\begin{tabular}{|c|c|c|c|c|c|c|}
\hline & England: inhalers/year & $\begin{array}{l}\text { England: } \\
\% \text { MDI }\end{array}$ & Sweden: inhalers/year & $\begin{array}{l}\text { Sweden: } \\
\% \text { MDI }\end{array}$ & $\begin{array}{l}\text { England: } \\
\mathrm{CO}_{2} \mathrm{e}(\mathrm{kt}) \text { per year }\end{array}$ & $\begin{array}{l}\text { England: } \\
\text { potential annual } \\
\text { reduction of } \mathrm{CO}_{2} \mathrm{e}(\mathrm{kt})\end{array}$ \\
\hline SABA & 21931511 & 94 & 1477692 & 10 & 414.00 & 350.0 \\
\hline LABA & 700195 & 65 & 377415 & 2 & 9.30 & 8.4 \\
\hline SAMA & 421191 & 100 & No data & 100 & 8.40 & 0 \\
\hline ICS & 6733445 & 94 & 765796 & 15 & 127.00 & 101.0 \\
\hline $\mathrm{ICS}+\mathrm{LABA}$ & 14075067 & 47 & 1719428 & 13 & 140.00 & 91.0 \\
\hline LAMA and LAMA+LABA & 6549448 & 0 & 428732 & 0 & 6.55 & 0 \\
\hline LAMA+LABA + ICS & 5211 & 99 & 2626 & 100 & -0.10 & 0 \\
\hline Total & 49994877 & 70 & 4771689 & 13 & 705.0 & 550.0 \\
\hline
\end{tabular}

Analysis uses 2017 community prescribing data from the NHS in England (https://digital.nhs.uk/) and assumes carbon footprint of MDI is $20 \mathrm{~kg} \mathrm{CO} \mathrm{Ca}_{2}$ and DPI is $1 \mathrm{~kg} \mathrm{CO}_{2} \mathrm{e}$. SAMA not included in analysis, as no DPI SAMA alternative is available. Potential annual reduction shows the hypothetical carbon savings if England were to prescribe the same proportions of MDI as Sweden.

DPI, dry powder inhaler; ICS, inhaled corticosteroid; LABA, long-acting $\beta_{2}$-agonist; LAMA, long-acting muscarinic antagonist; MDI, metered dose inhaler; SABA, short-acting $\beta_{2}$ agonist; SAMA, short-acting muscarinic antagonist.

to approximately $2.6 \%$ of the total carbon footprint for NHS England. ${ }^{9}$ The main weakness of this analysis was that the analysis was limited to GlaxoSmithKline devices as accurate carbon footprint data were not available from other manufacturers.

Key considerations for inhaler selection include healthcare professional knowledge of all the devices; inhalation manoeuvre achieved; airway disease severity, patient's ability to use their device correctly and their personal preferences. ${ }^{10}$ Thus the final choice of inhaler includes many factors, such as the fundamental efficacy of the molecules, patient-use factors, and the environmental burden. It should be noted that any change from an MDI to DPI device in clinical practice should be based on a clinical assessment and needs to be actively supported by appropriate programmes of education and assessment to ensure correct inhaler technique.

We conclude that Ellipta and Accuhaler DPIs have considerably lower carbon footprints than Evohaler MDIs, at both an individual and a national level. The lower carbon footprint of DPIs should be considered alongside other factors for patients who are able to use these devices effectively.

Twitter Alexander J K Wilkinson @DrAlexWilkinson

Acknowledgements The authors gratefully acknowledge the assistance of Luke Hedger, GlaxoSmithKline plc., in analysing the inhaler carbon footprint data for this manuscript.

Contributors The authors declare the following contributions to this study: AJKW, $\mathrm{CJ}, \mathrm{ML}$ and RH developed the study concept; $\mathrm{AJKW}, \mathrm{CJ}$ and $\mathrm{RH}$ were involved in the data analysis; all authors contributed to drafting and finalising the manuscript and approved the final version for submission; $\mathrm{CJ}$ is the guarantor, taking responsibility for work and/or conduct of study, full access to data, and control of decision to publish.

Funding Editorial support (in the form of collating author comments, assembling tables/figures, grammatical editing and referencing) was provided by Jenni Lawton, $\mathrm{PhD}$, of Gardiner-Caldwell Communications (Macclesfield, UK), and was funded by GlaxoSmithKline.

Competing interests All authors have completed the ICMJE uniform disclosure form at www.icmje.org/coi_disclosure.pdf and declare the following: CJ reports personal fees from AstraZeneca, Boehringer Ingelheim, Chiesi, GlaxoSmithKline, Novartis and TEVA outside the submitted work; $\mathrm{MH}$ reports honoraria from GlaxoSmithKline for presenting scientific data on climate change; AJKW has nothing to disclose; RH and RS are GlaxoSmithKline employees and hold GlaxoSmithKline stocks/shares, ML is an employee of GlaxoSmithKline.
Patient consent for publication Not required.

Provenance and peer review Not commissioned; externally peer reviewed.

Open access This is an open access article distributed in accordance with the Creative Commons Attribution Non Commercial (CC BY-NC 4.0) license, which permits others to distribute, remix, adapt, build upon this work non-commercially, and license their derivative works on different terms, provided the original work is properly cited, appropriate credit is given, any changes made indicated, and the use is non-commercial. See: http://creativecommons.org/licenses/by-nc/4.0/.

\section{ORCID iDs}

Christer Janson http://orcid.org/0000-0001-5093-6980

Alexander J K Wilkinson http://orcid.org/0000-0002-1808-3663

\section{REFERENCES}

1 United Nations. Montreal protocol on substances that deplete the ozone layer. Available: http://www.un-documents.net/mpsdol.htm [Accessed 7 Nov 2018].

2 Lavorini F, Corrigan CJ, Barnes PJ, et al. Retail sales of inhalation devices in European countries: so much for a global policy. Respir Med 2011;105:1099-103.

3 British Thoracic Society. The environment and lung health. Available: https://www. brit-thoracic.org.uk/document-library/governance-and-policy-documents/positionstatements/environment-and-lung-health-position-statement-2019/ [Accessed 3 May 2019].

4 NHS Digital. Prescription cost analysis: England, 2017, 2018. Available: https:// digital.nhs.uk/data-and-information/publications/statistical/prescription-cost-analysis/ prescription-cost-analysis-england-2017 [Accessed 7 Nov 2018].

5 Montreal protocol on substances that deplete the ozone layer. Report of the UNEP medical technical options Committee, 2014 assessment. Available: http:// conf.montreal-protocol.org/meeting/oewg/oewg-36/presession/Background\% 20Documents \%20are\%20available\%20in\%20English\%20only/MTOC-AssessmentReport-2014.pdf [Accessed 11 Jan 2019].

6 Climate \& Clean Air Coalition. Hydrofluorocarbons (HFC). Available: https://www. ccacoalition.org/fr/slcps/hydrofluorocarbons-hfc [Accessed 19 of Aug 2019].

7 Wynes S, Nicholas KA. The climate mitigation gap: education and government recommendations miss the most effective individual actions. Environ Res Lett 2017;12.

8 Vestbo J, Papi A, Corradi M, et al. Single inhaler extrafine triple therapy versus long-acting muscarinic antagonist therapy for chronic obstructive pulmonary disease (TRINITY): a double-blind, parallel group, randomised controlled trial. Lancet 2017;389:1919-29.

9 NHS England sustainable development unit. Reducing the use of natural resources in health and social care 2018 report. Available: https://www.sduhealth.org.uk/ policy-strategy/reporting/natural-resource-footprint-2018.aspx [Accessed 20 Jun 2019].

10 British Thoracic Society/Scottish Intercollegiate Guidelines Network. British guideline on the management of asthma, 2019. Available: https://www.brit-thoracic.org. uk/standards-of-care/guidelines/btssign-british-guideline-on-the-management-of asthma/ [Accessed 14 Dec 2018] 